\title{
Bioabsorbable high-purity magnesium interbody cage: degradation, interbody fusion, and biocompatibility from a goat cervical spine model
}

\author{
Xiuwu Guo" ${ }^{1 \#}$, Haocheng $\mathrm{Xu}^{2 \#}$, Fan Zhang ${ }^{2}$, Feizhou $\mathrm{Lu}^{1}$ \\ ${ }^{1}$ Department of Orthopedics, The Fifth People's Hospital of Shanghai, Fudan University, Shanghai, China; ${ }^{2}$ Department of Orthopedics, Huashan \\ Hospital, Fudan University, Shanghai, China \\ Contributions: (I) Conception and design: X Guo, H Xu, F Lu; (II) Administrative support: F Lu; (III) Provision of study materials or patients: All \\ authors; (IV) Collection and assembly of data: All authors; (V) Data analysis and interpretation: X Guo, H Xu; (VI) Manuscript writing: All authors; \\ (VII) Final approval of manuscript: All authors. \\ \#These authors contributed equally to this work. \\ Correspondence to: Fan Zhang. Department of Orthopedics, Huashan Hospital, Fudan University, No. 12 Wulumuqi Middle Road, Shanghai, China. \\ Email: zfdtc@126.com; Feizhou Lu. Department of Orthopedics, The Fifth People's Hospital of Shanghai, Fudan University, Shanghai, China. \\ Email: lufeizhou@hotmail.com.
}

Background: Bioabsorbable Mg-based implants have been a focus of orthopedic researches due to their intrinsic advantages in orthopedics surgeries. This study aimed to investigate the performance of bioabsorbable high-purity magnesium (HP Mg, 99.98 wt.\%) interbody cages in anterior cervical discectomy and fusion (ACDF) and to evaluate the degradation of $\mathrm{HP} \mathrm{Mg}$ cages under an interbody microenvironment. Methods: ACDF was performed at C2-3 and C4-5, and a HP Mg cage or autologous iliac bone was randomly implanted. At 3, 6, 12 and 24 weeks after surgery, the cervical specimens were harvested to evaluate the fusion status, degradation and biocompatibility by CT, micro-CT, histological examinations and blood tests.

Results: There was no significant difference in the CT fusion score between cage group and autogenous ilium group at 3 and 6 weeks. At 12 and 24 weeks, the mean CT fusion score in the cage group was markedly lower than in the autogenous ilium group. CT and histological examinations showed bony junctions formed through the middle hole of the cage between upper and lower vertebral bodies in the cage group, but the total fusion area was less than $30 \%$. The degradation rate of cages was relatively rapid within the first 3 weeks and thereafter became stable and slow gradually. The HP Mg cage had good biosecurity and biomechanical characteristics.

Conclusions: Implantation of Mg-based interbody cage achieves successful histological fusion, while the total fusion area needs to be improved. More studies are needed to improve the bone-cage interface.

Keywords: Anterior cervical discectomy and fusion (ACDF); high-purity magnesium (HP Mg); bioabsorbable interbody cage

Submitted Jan 03, 2020. Accepted for publication Aug 07, 2020.

doi: $10.21037 /$ atm-20-225

View this article at: http://dx.doi.org/10.21037/atm-20-225

\section{Introduction}

The anterior cervical discectomy and fusion (ACDF) has been a standard treatment for cervical degenerative disease. Autologous iliac bone implantation is a gold standard for the intervertebral fusion, but patients still have long-lasting pain, damage to blood supply and infection at the site of implantation (1-3). The introduction of interbody fusion cage in ACDF avoids some complications such as pain and 


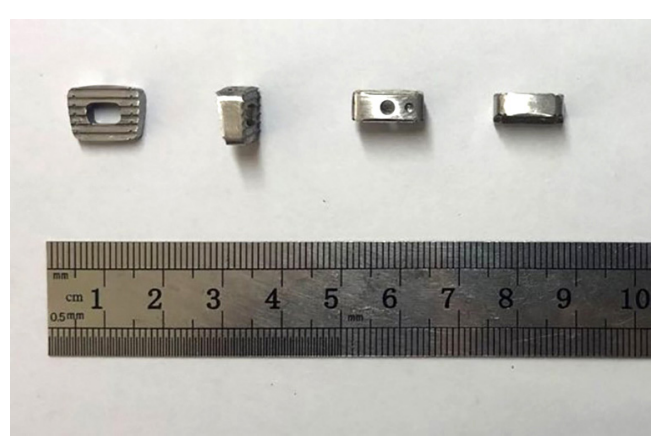

Figure 1 The conformation of $\mathrm{HP} \mathrm{Mg}$ case. $\mathrm{HP} \mathrm{Mg}$, high-purity magnesium.

infection of the donor bone caused by autologous ilium and xenograft, bone graft collapse and immune rejection, and thus interbody fusion cage has been widely used in clinical practice. Currently, the commonly used cervical interbody fusion cage is mainly made of non-absorbable materials such as polyether ether ketone (PEEK) and titanium, which may cause implant subsidence and segment instability, and induce chronic inflammatory response $(4,5)$. By contrast, the biological absorbable magnesium $(\mathrm{Mg})$ and its alloys have favorable biocompatibility and osteogenic induction ability, and their mechanical properties are similar to human bone (6-8). Thus, they have become the ideal materials for cervical interbody fusion cage.

Success has been achieved in $\mathrm{Mg}$ implants in in vivo studies on the unforced bones such as AZ31 screws in rabbit mandible and $\mathrm{MgCa}_{0.8}$ alloy screws in rabbit tibiae $(9,10)$. However, in the ACDF model of goat cervical vertebrae bearing force, although the development of $\mathrm{Mg}$ alloys composition and the addition of surface coating methods to improve the degradation of $\mathrm{Mg}$-based cage, such as an AZ31 cage with poly- $\varepsilon$-caprolactone (PCL) coating, porous $\mathrm{Mg}$-Zinc $(\mathrm{Zn})$ alloy cage with a microarc oxidation (MAO)/silicon- (Si-) containing coating and AZ31 cage with Si-containing coating, the whole degradation rate was nonlinear in the 24-week observation period, the early degradation rate was relatively fast, which resulted in the formation of local $\mathrm{Mg}$ ion concentration in tissues. Thus, the bone healing is still poor after implantation of $\mathrm{Mg}$-based cage, and fusion success has never been reported (11-13). The main barrier that limits the clinical application of $\mathrm{Mg}$ based cages is adverse reactions secondary to their fast degradation which may be caused by intervertebral pressure and blood supply different from unforced bones (14).

However, the improvement of $\mathrm{Mg}$ purification significantly improves the degradation resistance of $\mathrm{Mg}$ based materials. There is evidence showing that the degradation rate of high-purity $\mathrm{Mg}(\mathrm{HP} \mathrm{Mg})$ is significantly slower than that of most $\mathrm{Mg}$ alloys (15). It has been reported that HP Mg screw has good bone integration ability and adequate mechanical strength in the body after implantation (16). Studies have been conducted to investigated the long-term degradation and the influence of degradation products of $\mathrm{HP} \mathrm{Mg}$ screw on microenvironment and recipient systems. Results indicate that the HP Mg screw has low degradation rate, good bone repair ability and longterm local/systemic biosafety, which may become a promising bone fixing tool (17). Based on the findings from the available studies about the application of $\mathrm{Mg}$-based materials in the unforced bone and cervical vertebra, we developed a new HP $\mathrm{Mg}$-based cervical interbody fusion cage. This study aimed to investigate the performance of this bioabsorbable $\mathrm{HP} \mathrm{Mg}$ cage in ACDF and to evaluate the effects of its degradation on the local microenvironment and recipient systems. We present the following article in accordance with the ARRIVE reporting checklist (available at http://dx.doi.org/10.21037/ atm-20-225).

\section{Methods}

\section{Implants}

The experimental bioabsorbable cage was constructed from $\mathrm{HP} \mathrm{Mg}$ with a small quantity of $\mathrm{Si}(99.982 \mathrm{wt} . \% \mathrm{Mg}$; 0.0178 wt. \% Si; <0.001 wt.\% Fe; <0.001 wt.\% Al). According to our previous findings, the size of experimental cage was modified with the specification of $12 \mathrm{~mm} \times$ $10 \mathrm{~mm} \times 4-5 \mathrm{~mm}$ and a 7 -degree wedge angle (Figure 1) $(12,13)$. The cage was tested in a universal testing machine, the modulus of elasticity in compression was $609.43 \pm 52.16 \mathrm{MPa}$, the yield strength was $151.59 \pm 8.34 \mathrm{MPa}$ and the compressive strength was $392.62 \pm 16.23 \mathrm{MPa}$, suggesting that the cage met the mechanical requirements for the cervical interbody implantation. All cages were rinsed in acetone and ethanol, then washed with distilled water, and finally sterilized by ${ }^{60} \mathrm{Co}$ radiation.

\section{Animals and surgery}

This study was approved by the Institutional Animal Care and Use Committee (IACUC) at the Department of Laboratory Animal Science, Fudan University (No. 20161053-A357) and followed the Institutional Guidelines 

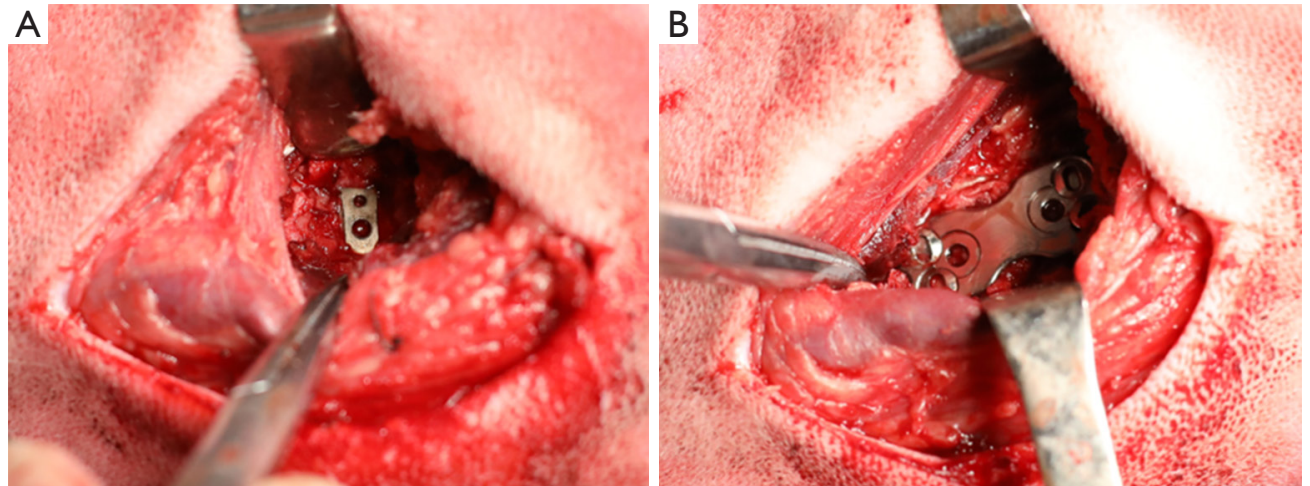

Figure 2 The operation of ACDF in a goat cervical spine model. (A) Implantation of HP Mg cage in goat ACDF; (B) fixation with titanium plate and screws in goat ACDF. ACDF, anterior cervical discectomy and fusion; HP Mg, high-purity magnesium.

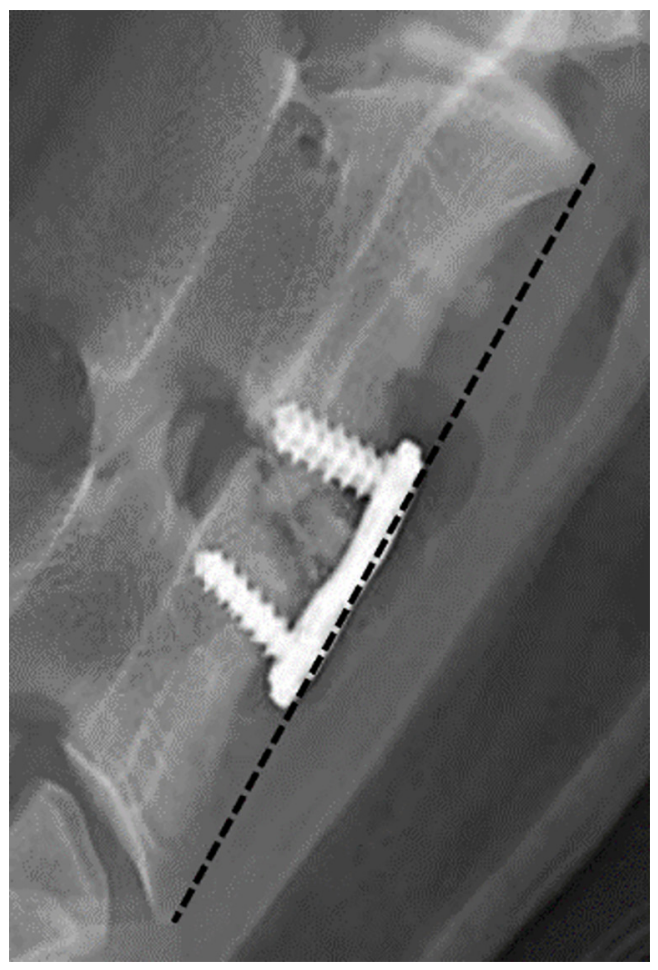

Figure 3 Lateral radiography of the goat neck. The length of black dot line was the distance between the upper front edge of upper vertebral body and the lower front edge of lower vertebral body.

for the care and use of animals. Twenty-four healthy 2 -year-old goats (12 females and 12 males) weighing $48.17 \pm 5.48$ (range, 40-57) $\mathrm{kg}$ were purchased from the Department of Laboratory Science, Fudan University. All the animals were housed in the Experimental Center of National Organization Engineering Research Center and given ad libitum access to sterilized water and food.

The goats received general anesthesia with $2.5 \%$ pentobarbital sodium for surgery. ACDF was performed at $\mathrm{C} 2-3$ and $\mathrm{C} 4-5$, and one of the two segments was randomly selected for implantation with an HP Mg cage (the cavity in the middle of cage is filled with autogenous iliac bone, and the surface area of the middle-hole plane accounts for about $20 \%$ ), while the other was implanted with autologous iliac bone followed by titanium plate and screws fixation (Figure $2 A, B$ ).

The goats were assessed at 3, 6, 12 and 24 weeks after surgery and 6 goats were randomly selected at each time point. In brief, the goats were killed after intravenous injection of potassium chloride following general anesthesia with pentobarbital sodium, and the treated segments were harvested for further examinations. At each time point, the segments with cages served as cage group and the segments with autologous iliac bone grafts as controls.

\section{Radiological examination}

Lateral radiography was done immediately after the surgical implantation and before sacrifice to determine any gas accumulation, disc space height (DSH) and implant subsidence. The change of DSH $(\triangle \mathrm{DSH})$ was calculated as the difference between height $\mathrm{A}$ and height $\mathrm{B}$, where the distance from the upper front edge of vertebral body fixed by the upper screw of titanium plate to the lower front edge of vertebral body fixed by the inferior screw of titanium plate was height B (Figure 3) which was measured during follow up period, and height A was measured immediately after operation; positive $\triangle \mathrm{DSH}$ value suggested the decreased postoperative vertebral body height. 


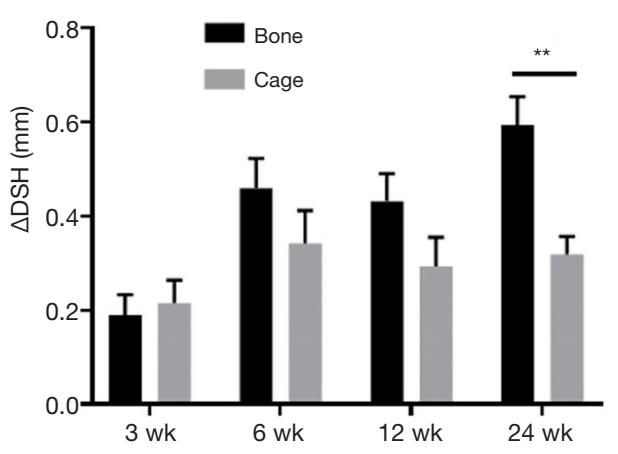

Figure $4 \Delta \mathrm{DSH}$ of the segments after different treatments. Significant difference was not observed in the $\triangle \mathrm{DSH}$ at 3, 6 and 12 weeks between two groups $(\mathrm{P}>0.05)$. $\Delta \mathrm{DSH}$ in the cage group was significantly smaller than in the autogenous ilium group at 24 weeks $(\mathrm{P}=0.003<0.05)$. **, $\mathrm{P}<0.01 . \Delta \mathrm{DSH}$, the change of disc space height.

A high-resolution CT was conducted before sacrifice at each time point to evaluate the interbody fusion. With a sagittal reconstruction of the CT images, the interbody fusion was evaluated based on a scoring system reported by Goldschlager et al:: 0, no new bone formation; 1, new bone formation but not continuous between $\mathrm{C} 2-3$ and $\mathrm{C} 4-5$; 2 , continuous bridging new bone but fusion area $<30 \% ; 3$, continuous bridging new bone but fusion area $>30 \%$ (18). CT was performed using a GE LightSpeed16 Slice CT Scanner (GE Healthcare, Milwaukee, WI, USA) with 0.63$\mathrm{mm}$ slice thickness and $0.63-\mathrm{mm}$ interval.

\section{Degradation assay}

Micro-CT was done to quantitate cage degradation. Based on the difference in the density between HP Mg cage and surrounding tissues, the volume of remaining cage was calculated from the $3 \mathrm{D}$ reconstructed images. The degradation rate was calculated as the volumetric percentage loss of the cage at different time points.

\section{Histological examination}

After fixation in paraformaldehyde, dehydration by acetone, and embedding in methyl methacrylate, the tissues at 24 weeks were cut into undecalcified tissue slices. Then, these slices were cut with a diamond band saw (EXAKT 300, Norderstedt, Germany) into 300- $\mu$ m sections, which were ground with a plate grinder (EXAKT 310, Norderstedt, Germany) to 20- $\mu \mathrm{m}$ sections. Four sections were taken near the midline of the sagittal sections and subjected to toluidine blue staining, van gieso staining, hematoxylin-eosin (HE) staining and Masson staining to examine the degree of osteogenesis and inflammatory response.

\section{Biocompatibility assay}

Blood samples were collected before surgery and at each time point after surgery. Parameters, such as $\mathrm{Mg}$ ion concentration, serum glutamic-pyruvic transaminase (ALT), serum glutamic oxalacetic transaminase (AST), serum creatinine (CREA) and urine creatinine (UREA), were detected to determine the biocompatibility of the HP Mg cage.

Tissues (heart, liver, spleen, lung and kidney) were collected and embedded in paraffin, and 2-3 $\mu \mathrm{m}$ sections were prepared using a microtome (RM 2016, Leica, Shanghai, China). These sections were subjected to HE staining for histological examination.

\section{Statistical analysis}

Statistical analyses were performed by using SPSS version 18.0 (Statistical Product and Service Solutions, Chicago, IL, USA). The $\triangle \mathrm{DSH}$ and CT fusion scores were compared with independent samples $t$-tests. The paired $t$-test was used to compare the hematological parameters. $\mathrm{P}<0.05$ was considered statistically significant.

\section{Results}

\section{Radiographical findings}

No significant difference was found in $\triangle \mathrm{DSH}$ between cage group and autogenous ilium group at 3, 6 and 12 weeks $(\mathrm{P}>0.05)$. At 24 weeks, the mean $\triangle \mathrm{DSH}$ in the cage group was significantly smaller than in the autogenous ilium group $(\mathrm{P}<0.05)$ (Figure 4). During the observation period, obvious settlement of implant was not observed in both groups.

The interbody fusion was evaluated after high-resolution CT. After surgery, there was no significant difference in the CT fusion score between cage group and autogenous ilium group at 3 and 6 weeks $(P>0.05)$. At 12 and 24 weeks, the mean CT fusion score in the cage group was markedly lower than in the autogenous ilium group $(\mathrm{P}<0.05)$ (Figure $5 A)$. At 24 weeks, bony junctions formed through the middle hole of the fusion cage between the upper and lower vertebral bodies in the cage group, but the total fusion area 

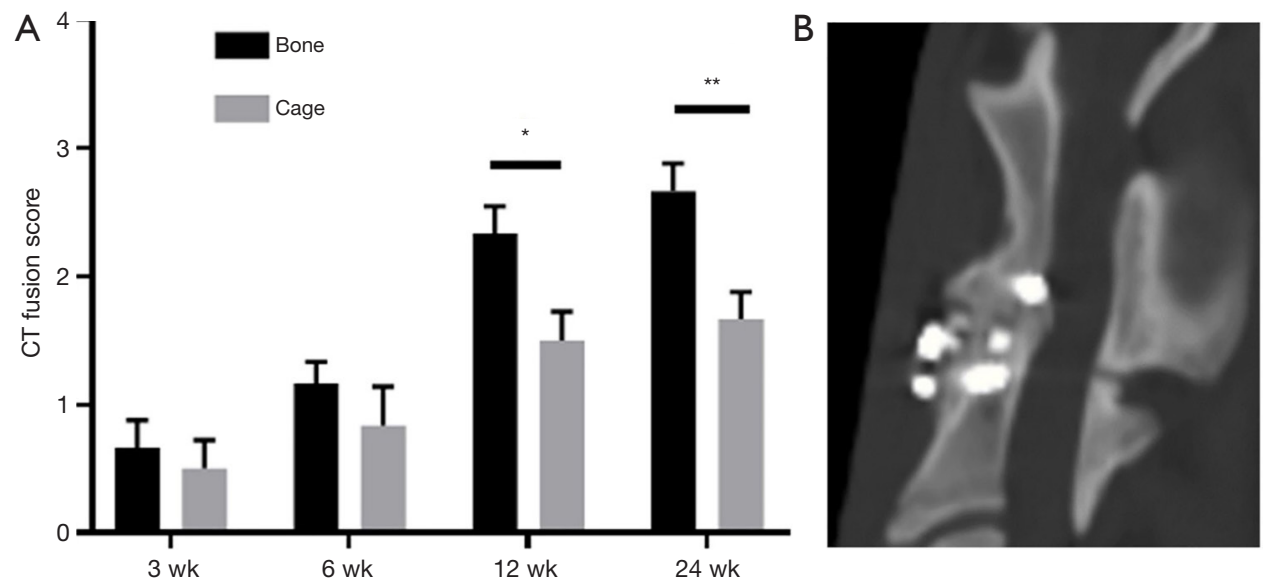

Figure 5 CT fusion scores of the segments after different treatments. (A) The fusion score in the autogenous ilium group was significantly higher than in the cage group at 12 and 24 weeks $(\mathrm{P}=0.022$ and $\mathrm{P}=0.007$, respectively). No significant difference was observed in the fusion score at 3 and 6 weeks between two groups. * $\mathrm{P}<0.05 ;{ }^{* *}, \mathrm{P}<0.01 ;(\mathrm{B})$ in the cage group, bony junctions formed through the middle hole of the fusion cage between the upper and lower vertebral bodies, but the total fusion area was less than $30 \%$.

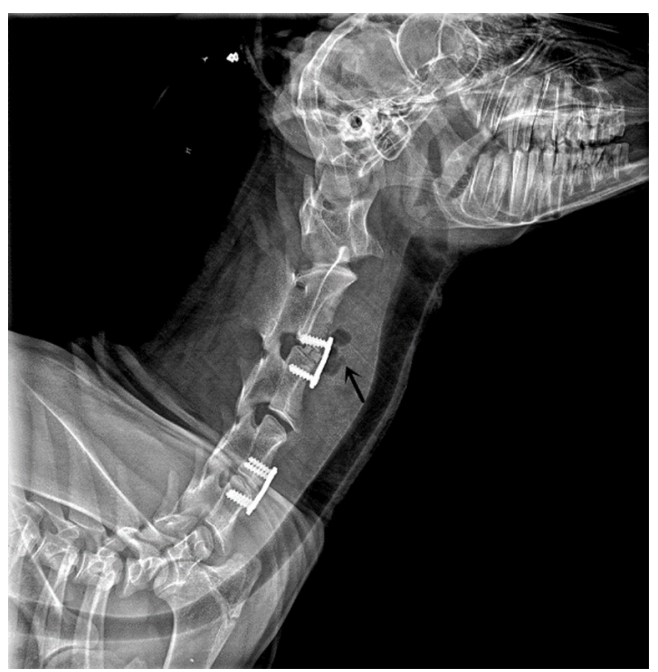

Figure 6 The black arrow displayed the gas accumulation in the space before the vertebrae.

was less than $30 \%$ (Figure 5B). The total fusion area of the autograft group at 24 weeks was $71.17 \% \pm 34.92 \%$.

Seven $(29.2 \%)$ goats had gas accumulation (Figure 6) before the disc space after implantation of the HP Mg cage (Figure 3 ) at 3 weeks (6/6) and 6 weeks (1/6), but not at 12 and 24 weeks.

\section{Degradation rate}

The degradation rate of the cages was relatively rapid within the first 3 weeks and thereafter became stable and slow gradually. The average volume decrease of the cages was $9.40 \% \pm 2.75 \%$ at 3 weeks, $11.77 \% \pm 2.17 \%$ at 6 weeks, $13.00 \% \pm 2.35 \%$ at 12 weeks and $13.73 \% \pm 2.62 \%$ at 24 weeks (Figure 7).

\section{Histological findings}

Similar to the CT findings, bony junctions formed through the middle hole of the fusion cage between the upper and lower vertebral bodies, and some of bone trabeculae formed continuous bone bridges which were bulky and dense between the endplate and the implanted autogenetic iliac bone at 24 weeks. However, the total fusion area was less than $30 \%$. There was a $300-400 \mu \mathrm{m}$ space between the bone tissues close to the cage, which was filled by the hyperplastic fibrous tissues. There was no evident infiltration of inflammatory cells, osteonecrosis, granuloma, and osteolysis in the space (Figure 8).

\section{Biocompatibility}

The serum $\mathrm{Mg}$ ion concentration, ALT, AST, CREA and UREA remained stable at 3, 6, 12, and 24 weeks after surgery (Figure 9).

The histological examination showed, at 24 weeks after $\mathrm{HP} \mathrm{Mg}$ cage implantation, there were no obvious pathological changes in the important tissues such as heart, liver, spleen, lung and kidney (Figure 10). 
A

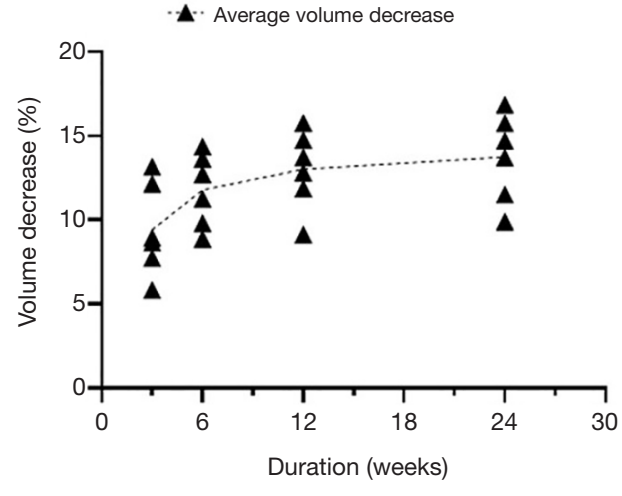

$\mathrm{D}$

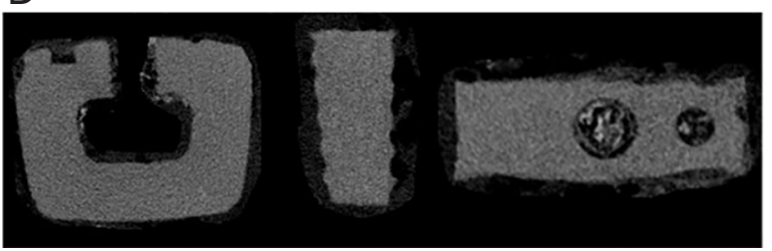

B

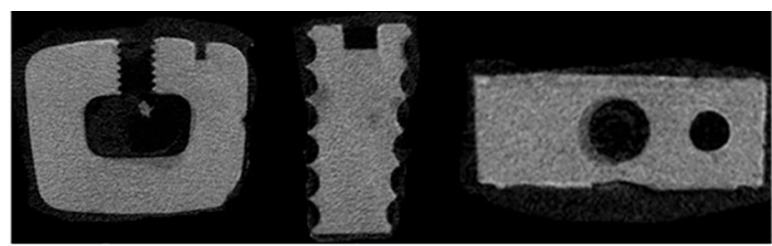

C
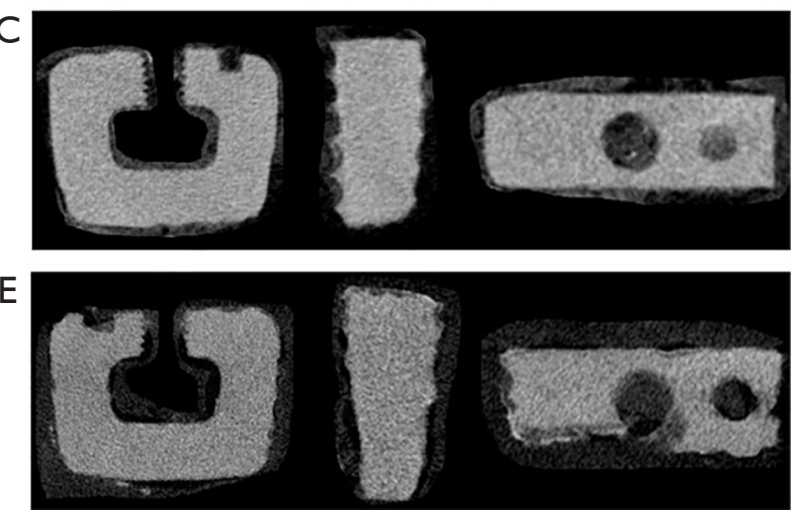

Figure 7 Volume decrease of the cages at different time points. (A) The degradation rate was relatively fast within the first 3 weeks and became slower thereafter; (B,C,D,E) the morphology of HP Mg cage on micro-CT at 3, 6, 12 and 24 weeks. HP Mg, high-purity magnesium.
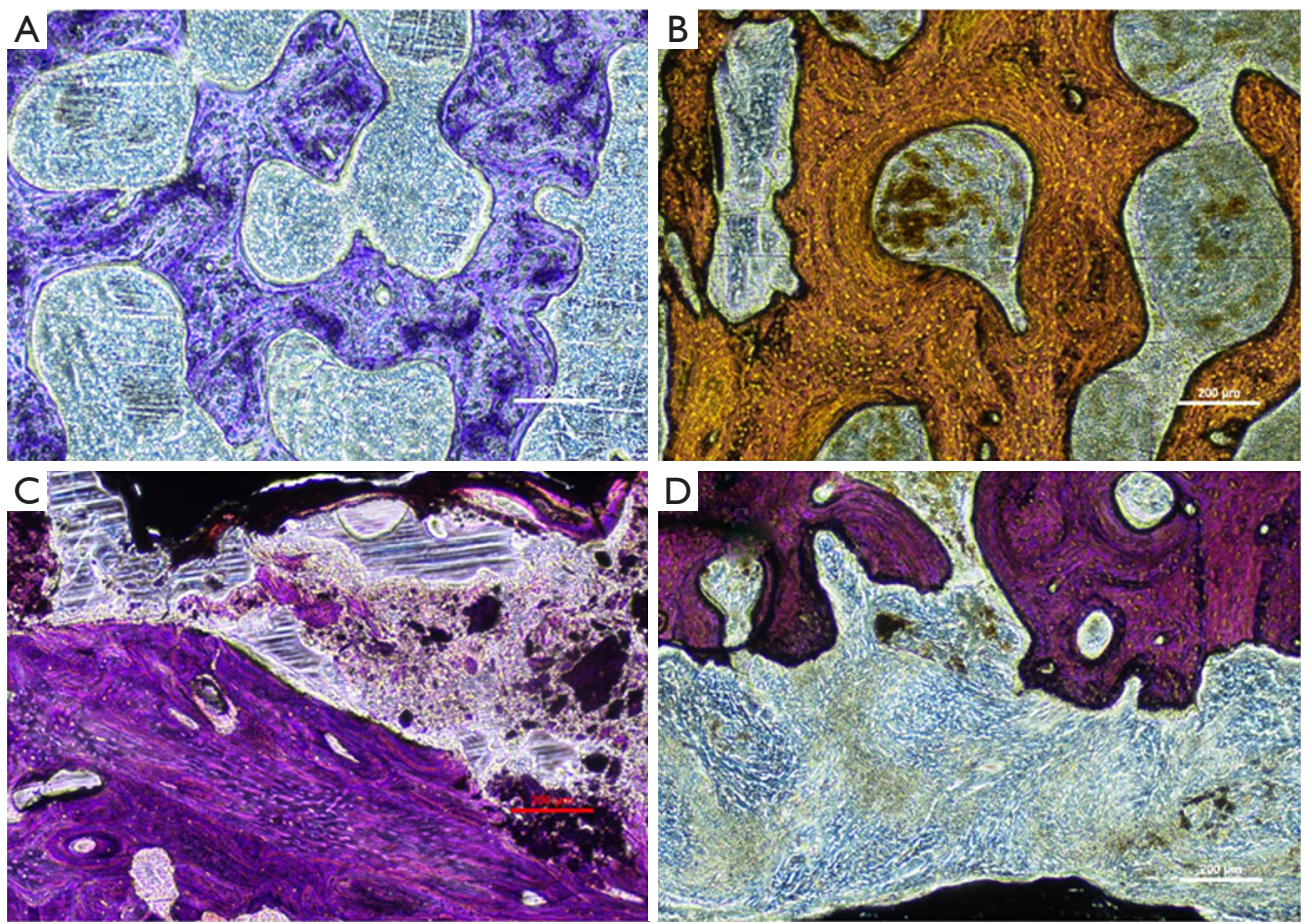

Figure 8 Histological sections after 24 weeks after operation (scale bars =200 $\mu \mathrm{m}$ ). (A) Toluidine blue staining and (B) van gieso staining showed bony junctions formed through the middle hole of the fusion device between the upper and lower vertebral bodies, and some of bone trabeculae formed continuous bone bridges which were bulky and dense; (C) HE staining and (D) Masson staining showed a 300-400 $\mu \mathrm{m}$ space between the bone tissues close to the cage, which was filled by the hyperplastic fibrous tissues. There were no evident infiltration of inflammatory cells, osteonecrosis, granuloma, and osteolysis in the space. HE, hematoxylin-eosin. 

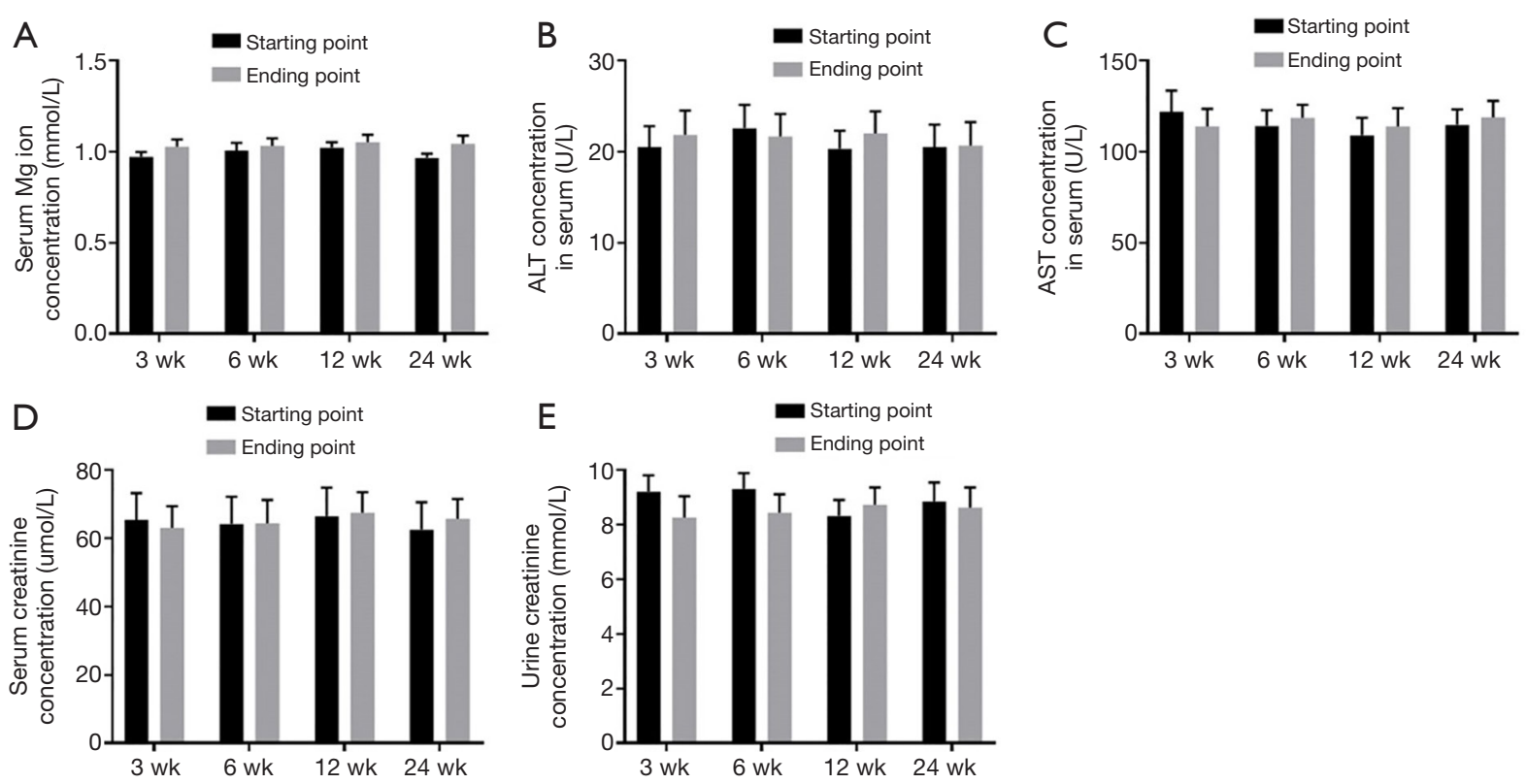

Figure 9 Serum biochemical parameters at different time points after treatment with the $\mathrm{HP} \mathrm{Mg}$ cage. (A) The serum Mg ion concentration, (B) ALT, (C) AST, (D) CREA, and (E) UREA remained stable after surgery (all P>0.05). HP Mg, high-purity magnesium; ALT, glutamicpyruvic transaminase; AST, glutamic oxalacetic transaminase; CREA, creatinine; UREA, urine creatinine.

\section{Discussion}

Due to the favorable biodegradability, good biocompatibility, and higher mechanical stability and ductility as compared to polymers, $\mathrm{Mg}$ and its alloys are widely used in the implants such as orthopedic implants, cardiovascular stents and biodegradable clips $(19,20)$. The $\mathrm{Mg}$-based implants in in vivo studies on unforced bones showed osteogenic inductivity leading to successful fusion. This may be explained as that $\mathrm{Mg}^{2+}$ released from $\mathrm{Mg}$ based implants plays a significant and positive role in the osteogenic differentiation mediated by neuronal calcitonin gene-related polypeptide (CGRP) (7). In available studies, the application of $\mathrm{Mg}$-based materials as a fusion cage fails in goat models (11-13). In the present study, our results for the first time indicated that $\mathrm{Mg}$ cage successfully induced intervertebral fusion which was confirmed histologically by the presence of bony junctions through the middle hole of the fusion cage between the upper and lower vertebral bodies at 24 weeks. Therefore, our findings provide a reference for the improvement of $\mathrm{Mg}$-based cages in the future, and also suggest that $\mathrm{Mg}^{2+}$ may induce osteogenesis through mechanisms other than periosteum induced osteogenesis.

Autograft has been used as a golden standard in ACDF, because it provides osteoconductive scaffolding, osteogenic cells as well as endogenous growth factors, and exhibits a high incorporation rate with early revascularization (1). Therefore, the autogenous ilium was used as a control in our study, but the use of autograft is significantly limited due to the elevated fracture rate, donor site morbidity and shortage of supply (21). In our study, the modulus of elasticity in compression, the yield strength and the compressive strength of HP Mg cage were similar to the human bones, suggesting the HP $\mathrm{Mg}$ cage meets the mechanical requirements. At 24 weeks, the HP Mg cage still maintained the favorable mechanical support. Moreover, the $\triangle \mathrm{DSH}$ of the segments at 24 weeks in the cage group was significantly smaller than in the control group.

In the clinical application of orthopedic devices, the degradation resistance of $\mathrm{Mg}$ and its alloys is a major issue. $\mathrm{Mg}$ dissolves in aqueous solution according to the following equations. Anodic reaction: $\mathrm{Mg} \rightarrow \mathrm{Mg}^{2+}+2 \mathrm{e}$. Cathodic reaction: $2 \mathrm{H}_{2} \mathrm{O}+2 \mathrm{e} \rightarrow \mathrm{H}_{2}+2 \mathrm{OH}^{-} ; \mathrm{Mg}^{2+}+2 \mathrm{OH}^{-} \rightarrow \mathrm{Mg}(\mathrm{OH})_{2}$. $\mathrm{Mg}(\mathrm{OH})_{2}$ layer may form on the $\mathrm{Mg}$ and its alloys implant, which may exert passivating effect and reduce the corrosion rate (16). However, the surface layer is not stable, compact and continuous enough to prevent the contact of underlying $\mathrm{Mg}$ surface with aggressive ions. In addition, there are a lot of chloride ions $\left(\mathrm{Cl}^{-}\right)$in the body fluid, and the $\mathrm{Cl}^{-}$ 

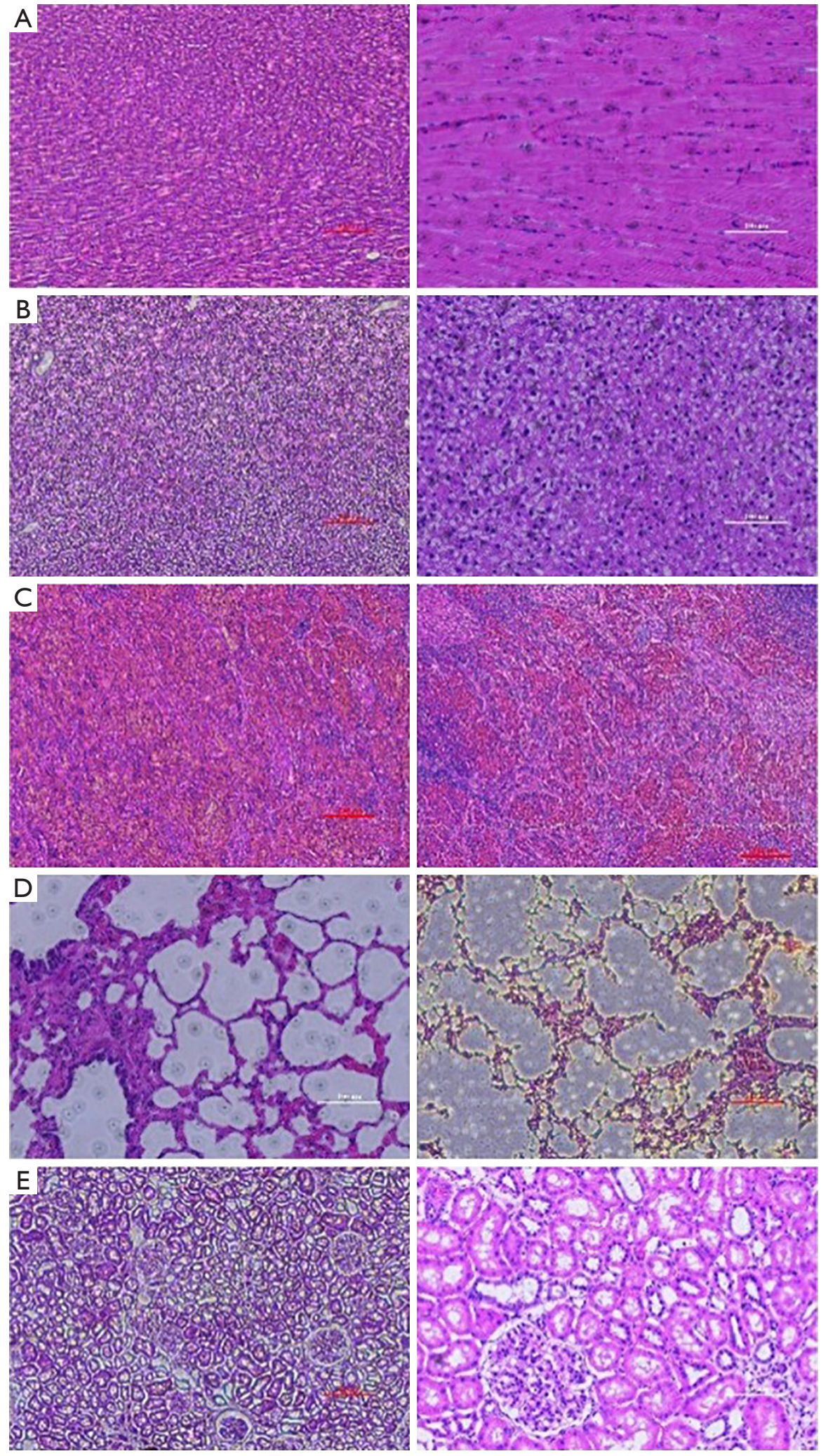

Figure 10 Histological findings of important tissues (HE staining) at 24 weeks after implantation. (A) Heart; (B) liver; (C) spleen; (D) lung; (E) kidney. Left scale bars $=200 \mu \mathrm{m}$; right scale bars $=100 \mu \mathrm{m}$. HE, hematoxylin-eosin. 
transforms $\mathrm{Mg}(\mathrm{OH})_{2}$ into soluble $\mathrm{MgCl}_{2}$, resulting in excess $\mathrm{OH}^{-}$ions in the solution (22). The blood supply to the postoperative interbody space and mechanical environment are different from those in the long bone after ACDF, which may attribute to the different degradation rates of $\mathrm{Mg}$-based materials at distinct anatomic structures, leading to the therapeutic failure. Our results showed the degradation rate was relatively fast within 3 weeks and thereafter remained stable, which was consistent with previously reported $(12,13,17)$. Moreover, the $300-400 \mu \mathrm{m}$ space around the HP $\mathrm{Mg}$ cage was filled with proliferative fibrous tissues, which may be ascribed to the early intrinsic response to the foreign body. This response induces the formation of a fibrotic capsule, and a stable $\mathrm{OH}^{-}$environment was maintained. However, the fibrotic capsule suppresses the effects of stress in vivo by protecting the corrosion surface (23). In our study, gas accumulation was noted at 3 weeks and in only 1 goat at 6 weeks, but it was absent at other time points. The gas accumulation may affect the bone healing, but our findings failed to find the adverse influence of gas accumulation on the following bone healing.

It has been reported that the corrosion of $\mathrm{Mg}$ and its alloys is sensitive to stress (24). The stress on the intervertebral space may induce the pitting corrosions and stress corrosion cracking, facilitating the $\mathrm{Mg}$ degradation, which forms a high-Mg environment and thereafter affects the bone healing and the mechanical support of the cage (25). In the present study, results showed the degradation became stable at 3 weeks after surgery. Although the surface corrosion was present, it had no significant influence on the bone healing and mechanical support. At 24 weeks after surgery, the cages still had favorable mechanical support, and intervertebral space collapse was not observed.

$\mathrm{Mg}$ purification is an effective way to improve the corrosion resistance of $\mathrm{Mg}$-based materials. The corrosion rate of $\mathrm{HP} \mathrm{Mg}$ is significantly slower than most of the other $\mathrm{Mg}$ alloys (15). It has been reported that the degradation rate of $\mathrm{HP} \mathrm{Mg}$ with a purity of $99.99 \%$ in vitro is only $10 \%$ of $\mathrm{Mg}$ with a purity of $99.9 \%$ (26). In our study, HP $\mathrm{Mg}$ with a purity of $99.98 \%$ was used, and its degradation rate was slow and stable. Moreover, there were no necrosis, infection foci or osteolytic reaction around the cage. This may be ascribed to the lack of impurities and the secondary phase (27). Micro-galvanic corrosion acceleration caused by the secondary phase may facilitate local corrosion and non-uniform degradation, then deteriorating the overall performance of degradable $\mathrm{Mg}$ implants. In addition, the pathophysiology and toxicology of alloying elements (such as $\mathrm{Al}$ and $\mathrm{SR})$ are also concerns $(28,29)$.

Biosafety examination showed the $\mathrm{Mg}$ ion concentration, ALT, AST, CREA and UREA remained stable after implantation of the HP Mg cage, and there was no microstructural alteration of the heart, liver, spleen and kidney on pathological examination after HE staining. This suggests that there are no large amounts of $\mathrm{Mg}$ ions quickly released into the blood, which is consistent with previous findings from $\mathrm{Mg}-1 \mathrm{Ca}$ and ZEK100 alloy (30). This supports the favorable biosafety of $\mathrm{HP} \mathrm{Mg}$ cage in vivo. The excessive $\mathrm{Mg}$ ions are not absorbed in the body and can be expelled via the urine. Thus, side effects caused by excessive $\mathrm{Mg}$ ions are rare in vivo (31).

This study for the first time reports vertebral fusion using a $\mathrm{Mg}$ fusion device, which indicates the possibility of application of $\mathrm{Mg}$-based cage in ACDF. Of note, the total fusion area is still smaller than $30 \%$. There is a $300-400 \mu \mathrm{m}$ space between the bone tissues close to the cage, which is filled by the hyperplastic fibrous tissues. The bone is not tightly bound to the fusion cage interface. These may be explained as follows: poor intervertebral blood supply, high local $\mathrm{Mg}^{2+}$ concentration which may inhibit osteogenic activity and increase osteoclast activity, and the lack of osteogenic induction ability at the interface (32). Thus, the structure and coating of $\mathrm{Mg}$-based materials should be further modified, aiming to improve the osteogenesis after implantation.

\section{Conclusions}

This is the first report of successful histological fusion for $\mathrm{Mg}$-based interbody cage: bony junctions form through the middle hole of the fusion cage between the upper and lower vertebral bodies, suggesting the possibility of clinical application of this cage. Of note, the fusion area is still smaller than $30 \%$, and the fusion results in the cage group are markedly worse than in the autogenous ilium group at 24 weeks. The degradation rate of the HP Mg cages is relatively fast within 3 weeks after implantation, but it remains stable and slow thereafter. The disc space of segments remains normal at least 24 weeks after implantation, indicating that $\mathrm{HP} \mathrm{Mg}$ cages have sufficient mechanical strength for interbody application. In addition, HP Mg cages have favorable biocompatibility without any systemic adverse reaction and adverse influence on important organs. Further investigations are needed to modify the Mg-based materials to balance the degradation rate of materials and the rate of bone healing, which is 
crucial for the future clinical application of these materials in ACDF.

\section{Acknowledgments}

Funding: This study was funded by National Natural Science Foundation of China (No. 81472056 and 81772385) and Aospine $\{$ No. AOSCN[R]2019-08\}.

\section{Footnote}

Reporting Checklist: The authors have completed the ARRIVE reporting checklist. Available at http://dx.doi. org/10.21037/atm-20-225

Data Sharing Statement: Available at http://dx.doi. org/10.21037/atm-20-225

Peer Review File: Available at http://dx.doi.org/10.21037/ atm-20-225

Conflicts of Interest: All authors have completed the ICMJE uniform disclosure form (available at http://dx.doi. org/10.21037/atm-20-225). The authors have no conflicts of interest to declare.

Ethical Statement: The authors are accountable for all aspects of the work in ensuring that questions related to the accuracy or integrity of any part of the work are appropriately investigated and resolved. This study was approved by the Institutional Animal Care and Use Committee (IACUC) at the Department of Laboratory Animal Science, Fudan University (No. 2016-1053-A357) and followed the Institutional Guidelines for the care and use of animals.

Open Access Statement: This is an Open Access article distributed in accordance with the Creative Commons Attribution-NonCommercial-NoDerivs 4.0 International License (CC BY-NC-ND 4.0), which permits the noncommercial replication and distribution of the article with the strict proviso that no changes or edits are made and the original work is properly cited (including links to both the formal publication through the relevant DOI and the license). See: https://creativecommons.org/licenses/by-nc-nd/4.0/.

\section{References}

1. Lalk M, Reifenrath J, Angrisani N, et al. Fluoride and calcium-phosphate coated sponges of the magnesium alloy AX30 as bone grafts: a comparative study in rabbits. J Mater Sci Mater Med 2013;24:417-36.

2. Silber JS, Anderson DG, Daffner SD, et al. Donor site morbidity after anterior iliac crest bone harvest for singlelevel anterior cervical discectomy and fusion. Spine (Phila Pa 1976) 2003;28:134-9.

3. Banwart JC, Asher MA, Hassanein RS. Iliac crest bone graft harvest donor site morbidity. A statistical evaluation. Spine (Phila Pa 1976) 1995;20:1055-60.

4. Maldonado-Naranjo AL, Healy AT, Kalfas IH. Polyetheretherketone (PEEK) intervertebral cage as a cause of chronic systemic allergy: a case report. Spine J 2015;15:e1-3.

5. Li ZJ, Wang Y, Xu GJ, et al. Is PEEK cage better than titanium cage in anterior cervical discectomy and fusion surgery? A meta-analysis. BMC Musculoskelet Disord 2016;17:379.

6. Seyedraoufi ZS, Mirdamadi S. Synthesis, microstructure and mechanical properties of porous $\mathrm{Mg}-\mathrm{Z} \mathrm{Zn}$ scaffolds. J Mech Behav Biomed Mater 2013;21:1-8.

7. Zhang Y, Xu J, Ruan YC, et al. Implant-derived magnesium induces local neuronal production of CGRP to improve bone-fracture healing in rats. Nat Med 2016;22:1160-9.

8. Huehnerschulte TA, Reifenrath J, von Rechenberg B, et al. In vivo assessment of the host reactions to the biodegradation of the two novel magnesium alloys ZEK100 and AX30 in an animal model. Biomed Eng Online 2012;11:14.

9. Henderson SE, Verdelis K, Maiti S, et al. Magnesium alloys as a biomaterial for degradable craniofacial screws. Acta Biomater 2014;10:2323-32.

10. Waizy H, Weizbauer A, Maibaum M, et al. Biomechanical characterisation of a degradable magnesium-based (MgCa0.8) screw. J Mater Sci Mater Med 2012;23:649-55.

11. Daentzer D, Willbold E, Kalla K, et al. Bioabsorbable interbody magnesium-polymer cage: degradation kinetics, biomechanical stiffness, and histological findings from an ovine cervical spine fusion model. Spine (Phila Pa 1976) 2014;39:E1220-7.

12. Xu H, Zhang F, Wang H, et al. Evaluation of a porous bioabsorbable interbody $\mathrm{Mg}-\mathrm{Zn}$ alloy cage in a goat cervical spine model. Biomed Res Int 2018;2018:7961509.

13. Zhang F, Xu H, Wang H, et al. Quantitative analysis of near-implant magnesium accumulation for a Si-containing coated AZ31 cage from a goat cervical spine fusion model. BMC Musculoskelet Disord 2018;19:105. 
14. Staiger MP, Pietak AM, Huadmai J, et al. Magnesium and its alloys as orthopedic biomaterials: a review. Biomaterials 2006;27:1728-34.

15. Qiao Z, Shi Z, Hort N, et al. Corrosion behaviour of a nominally high purity $\mathrm{Mg}$ ingot produced by permanent mould direct chill casting. Corrosion Science 2012;61:185-207.

16. Han $\mathrm{P}$, Cheng $\mathrm{P}$, Zhang $\mathrm{S}$, et al. In vitro and in vivo studies on the degradation of high-purity $\mathrm{Mg}$ (99.99wt.\%) screw with femoral intracondylar fractured rabbit model. Biomaterials 2015;64:57-69.

17. Yu Y, Lu H, Sun J. Long-term in vivo evolution of highpurity $\mathrm{Mg}$ screw degradation - Local and systemic effects of Mg degradation products. Acta Biomater 2018;71:215-24.

18. Goldschlager T, Rosenfeld JV, Ghosh P, et al. Cervical interbody fusion is enhanced by allogeneic mesenchymal precursor cells in an ovine model. Spine (Phila $\mathrm{Pa} 1976)$ 2011;36:615-23.

19. Chen $Y, X u Z$, Smith C, et al. Recent advances on the development of magnesium alloys for biodegradable implants. Acta Biomater 2014;10:4561-73.

20. Zhao D, Witte F, Lu F, et al. Current status on clinical applications of magnesium-based orthopaedic implants: a review from clinical translational perspective. Biomaterials 2017;112:287-302.

21. Nandi SK, Roy S, Mukherjee P, et al. Orthopaedic applications of bone graft \& graft substitutes: a review. Indian J Med Res 2010;132:15-30.

22. Zhang S, Zhang X, Zhao C, et al. Research on an Mg$\mathrm{Zn}$ alloy as a degradable biomaterial. Acta Biomater 2010;6:626-40.

23. Feins EN, Lee Y, O'Cearbhaill ED, et al. A growthaccommodating implant for paediatric applications. Nat

Cite this article as: Guo $\mathrm{X}, \mathrm{Xu} \mathrm{H}$, Zhang F, Lu F. Bioabsorbable high-purity magnesium interbody cage: degradation, interbody fusion, and biocompatibility from a goat cervical spine model. Ann Transl Med 2020;8(17):1054. doi: 10.21037/atm-20-225
Biomed Eng 2017;1:818-25.

24. Peron M, Torgersen J, Berto F. Mg and its alloys for biomedical applications: exploring corrosion and its interplay with mechanical failure. Metals 2017;7:252.

25. Gao Y, Wang L, Li L, et al. Effect of stress on corrosion of high-purity magnesium in vitro and in vivo. Acta Biomater 2019;83:477-86.

26. Xin $\mathrm{Y}, \mathrm{Hu} \mathrm{T}, \mathrm{Chu} \mathrm{PK}$. In vitro studies of biomedical magnesium alloys in a simulated physiological environment: a review. Acta Biomater 2011;7:1452-9.

27. Walter R, Kannan MB. A mechanistic in vitro study of the microgalvanic degradation of secondary phase particles in magnesium alloys. J Biomed Mater Res A 2015;103:990-1000.

28. Nattrass C, Horwell CJ, Damby DE, et al. The effect of aluminium and sodium impurities on the in vitro toxicity and pro-inflammatory potential of cristobalite. Environ Res 2017;159:164-75.

29. Gu XN, Xie XH, Li N, et al. In vitro and in vivo studies on a $\mathrm{Mg}$-Sr binary alloy system developed as a new kind of biodegradable metal. Acta Biomater 2012;8:2360-74.

30. Dziuba D, Meyer-Lindenberg A, Seitz JM, et al. Longterm in vivo degradation behaviour and biocompatibility of the magnesium alloy ZEK100 for use as a biodegradable bone implant. Acta Biomater 2013;9:8548-60.

31. Wong HM, Wu S, Chu PK, et al. Low-modulus Mg/PCL hybrid bone substitute for osteoporotic fracture fixation. Biomaterials 2013;34:7016-32.

32. Sun W, Zhang G, Tan L, et al. The fluoride coated AZ31B magnesium alloy improves corrosion resistance and stimulates bone formation in rabbit model. Mater Sci Eng C Mater Biol Appl 2016;63:506-11. 